
\title{
Research Suare \\ The Risk Characteristics of Heavy Metals in Urban Soil
}

\author{
Yan Li ( $\square$ lyle@njfu.edu.cn ) \\ Nanjing Forestry University \\ Dike Feng \\ Nanjing Forestry University \\ Meiying Ji \\ Nanjing Forestry University \\ Zhanpeng Li \\ Nanjing Forestry University \\ Ruocheng Zhang \\ Nanjing Forestry University \\ Chenwei Gu \\ Nanjing Forestry University
}

\section{Research Article}

Keywords: Nanjing city, soil, heavy metals, ecological risk, health risk

Posted Date: July 30th, 2021

DOI: https://doi.org/10.21203/rs.3.rs-516802/v1

License: (c) (i) This work is licensed under a Creative Commons Attribution 4.0 International License.

Read Full License 


\section{The risk characteristics of heavy metals in urban soil}

Yan Li*, Dike Feng, Meiying Ji, Zhanpeng Li, Ruocheng Zhang, Chenwei Gu

Collaborative Innovation Center of Sustainable Forestry, Nanjing Forestry University, Nanjing, Jiangsu, China

* Corresponding author: Yan Li

\section{Corresponding author:}

Yan Li, lyle@njfu.edu.cn

College of forestry, Nanjing Forestry University, 159 Longpan Road, Nanjing 210037, Jiangsu, China 
Abstract: With the rapid development of China's industrial economy, heavy metals and other pollutants continue to accumulate in the environment, which has created serious threats for the ecological environment and human health. To comprehensively evaluate the ecological risks from heavy metals in the soil in Nanjing, China, as well as the status of the risks to human health, this study randomly collected 50 surface soil samples, and the contents of $\mathrm{Al}, \mathrm{Ca}, \mathrm{Fe}, \mathrm{Mg}, \mathrm{Mn}$, $\mathrm{Ni}, \mathrm{Ti}, \mathrm{Cd}, \mathrm{Cr}, \mathrm{Cu}, \mathrm{Pb}$ and $\mathrm{Zn}$ in the samples were determined, combined with the ecological risk index and the USEPA health risk assessment model for a comprehensive risk assessment of soil heavy metals in Nanjing. The results show that there has been heavy metal enrichment of $\mathrm{Mn}, \mathrm{Pb}, \mathrm{Zn}$ and other heavy metals in the research area in Nanjing city, and the variation coefficients of $\mathrm{Pb}$ and $\mathrm{Cu}$ are distinctly large; that is, the distribution of $\mathrm{Pb}$ and $\mathrm{Cu}$ in the research area shows a great fluctuation. These elements are all slightly polluting, among which the $\mathrm{Cu}$ heavy metal pollution degree is different, and $\mathrm{Pb}$ element pollution is the most serious. Children are at a high risk of exposure in various ways, among which $\mathrm{Pb}$ and $\mathrm{Cu}$ elements have a high risk of causing non-carcinogenic issues. Overall, $\mathrm{Pb}$ and $\mathrm{Cu}$ in Nanjing are important risk elements that should be monitored and controlled. The results of the correlation analysis showed that the content changes of $\mathrm{Pb}, \mathrm{Zn}$ and $\mathrm{Cu} ; \mathrm{Ni}$, Ti and $\mathrm{Fe}$; and $\mathrm{Zn}$ and $\mathrm{Pb}$ had extremely significant correlations, indicating that they may have the same source; while $\mathrm{Ti}$ and $\mathrm{Ca}, \mathrm{Ti}$ and $\mathrm{Cu}$, and $\mathrm{Pb}$ and $\mathrm{Zn}$ showed opposite changes, indicating that their concentrations were inversely related. The results of the principal component analysis showed that industrial sources in Nanjing contributed the most heavy metals, reaching $34.4 \%$. The second largest source was from parent material and fertilizer, which contributed $32.3 \%$ and $19.6 \%$, respectively. The sources with the lowest contributions were from weathering and deposition, which reached $13.7 \%$.

Keywords: Nanjing city, soil, heavy metals, ecological risk, health risk

\section{Introduction}

Heavy metal pollution has had a large impact on a global scale. With the development of China's industrialization process, serious heavy metal pollution problems have emerged in the soil in urban areas. For example, smelters emit heavy metals through the combustion of fossil fuels and industrial emissions. The dust produced by smelters pollutes the surrounding soil with heavy metals ${ }^{[1]}$. In China, light and heavy metal pollution in soil accounts for $13.12 \%$ and $10.82 \%$ of the pollution, respectively, indicating that the problem of heavy metal pollution is not positive ${ }^{[2]}$. Heavy metal pollution is closely related to people's daily lives. Heavy metal elements in the soil may be mixed in dust and enter the human body through breathing, thus causing diseases, or they may discharge into the water, thereby polluting the water supply, which, in the case of humans, can lead to excessive levels of heavy metals in drinking water. In animals and plants, heavy metals can lead directly to death ${ }^{[3]}$. In addition, if crops are planted on land contaminated with 
heavy metals, heavy metal elements will also enter the human body through grain ${ }^{[4]}$. For example, if rice is planted in soils contaminated with lead and cadmium, there will also be a certain amount of heavy metals in the rice ${ }^{[5]}$. In addition, heavy metals have a long half-life and are not easy to degrade. Trace amounts of heavy metals can also cause harm to the human body, and serious cases may lead to the destruction of the central nervous system in the human body ${ }^{[6]}$. Soil heavy metals are a serious threat to the urban ecological environment and the health of urban residents; however from the view of large cities such as Nanjing, research on soil heavy metals has obvious deficiencies. (1) Sampling studies and their test data are many years old and were conducted when the economy of Nanjing was rapidly developing and its city population was rapidly increasing; therefore, new data on the heavy metals in the urban soil in Nanjing are urgently needed. (2) Research studies on the risk of heavy metals in urban soils have generally only considered ecological risk or human health risk assessments separately; thus, there is a lack of studies us ing both evaluation systems.

Based on this, in this study, we collected soil samples in Nanjing to detect the heavy metal composition of the soil and to analyse the degree of heavy metal pollution in the city soil. Nanjing, the capital city of Jiangsu Province in China, is located in the Yangtze River Basin, has rich natural resources and is a well-known area for fish and rice in China. It has a dense population, a large resident population and a large number of universities. The study of the heavy metal content in the soil of Nanjing is not only beneficial to local residents but also plays a warning role regarding the control of heavy metal pollution. By detecting the corresponding data for $\mathrm{Al}, \mathrm{Ca}, \mathrm{Fe}, \mathrm{Mg}, \mathrm{Mn}, \mathrm{Ni}, \mathrm{Ti}, \mathrm{Cd}, \mathrm{Cr}, \mathrm{Cu}, \mathrm{Pb}$ and $\mathrm{Zn}$ (among which, the five elements: $\mathrm{Cd}, \mathrm{Cr}, \mathrm{Cu}, \mathrm{Pb}$ and $\mathrm{Zn}$, are used for the calculation of the single factor index and geoaccumulation index), the ecological and health risks are evaluated based on these data. Soil heavy metals are particularly important to the environment and to human health. This study aims to analyse the ecological pollution of heavy metals in urban environments to evaluate the health risks. We hope this research can establish ecological risks of heavy metals and health risk evaluation systems, providing a theoretical basis for the prevention and control of heavy metal pollution in urban environments.

\section{Research Methods}




\subsection{Collection and Test}

\subsubsection{Collection of Soil Samples}

On September 10, 2020, we collected soil samples in Nanjing. To avoid accidental error and unstable factor interference, the accumulation of soil samples was conducted as far away as possible from obvious sources of pollution such as waste soil to avoid collecting from newly created sources of pollution; thereby, excluding the surface composition of the soil, eluvial soil and rocks, man-made waste, weeds, and fertilizers, utilizing clean pollution-free tools to collect all soil samples and ensuring that the chemical composition was relatively stable and typical of the soil profile. Sampling depth of the surface soil was $0-20 \mathrm{~cm}^{[7]}$. During the sampling process, the "diagonal point arrangement method" was adopted to place three subsample points at each sampling point, and approximately $200 \mathrm{~g}$ of surface soil was collected at each subsample point, which was fully mixed and placed into a self-sealing bag. The geographical location, altitude and surrounding environmental conditions at the sample sites were recorded. The soil samples were transported to the laboratory to be air-dried, crushed, ground, and screened (100 mesh) for later use.

\subsubsection{Determination of soil samples}

Approximately $100 \mathrm{mg}$ of ground soil sample was placed into a $25 \mathrm{~mL}$ polytetrafluoroethylene beaker for a series of digestion processes. The contents of $\mathrm{Zn}, \mathrm{Pb}, \mathrm{Cu}, \mathrm{Cr}$ and $\mathrm{Ni}$ were measured using an Optima 5300DV inductively coupled plasma emission spectrometer $(\mathrm{ICP}-\mathrm{A} \times 10 \mathrm{~S})$ produced by $\mathrm{P} \times 10 \mathrm{rkin} \times 10 \mathrm{LM} \times 10 \mathrm{R}$, USA. The content of Cd was determined by an inductively coupled plasma mass spectrometer $\times 10$ LAN9000 $(\mathrm{P} \times 10$ rkin $-\times 101 \mathrm{~m} \times 10 \mathrm{r}$, Inc., USA $)$. The ICP-A $\times 10 \mathrm{~S}$ and ICP-MS began to stabilize one hour after ignition and could be tested ${ }^{[8]}$. The best working conditions and the detection limits for the different elements were determined. To improve the accuracy of the elemental content test, standard material GBW07405 was tested every two samples for calibration.

\subsubsection{Planning and Determination of Sampling Points}


Nanjing is a typical industrial city with a serious problem of soil heavy metal pollution ${ }^{[9]}$. In 2019, Nanjing had a permanent population of 8.50 million people, including 7.072 million urban residents, accounting for 83.2 percent of the total urban population. It has a real population of $10,312,200$ people. The influence of heavy metal pollution on human health has always been the focus of social problems. To study the main activity area surrounding the heavy metal pollution area, we conducted gradient stationing in urban, suburban, village and town areas using satellite images and field investigations. According to population density and commercial prosperity, we determined 50 soil-sampling sites. The sampling distribution is shown in Figure 1.

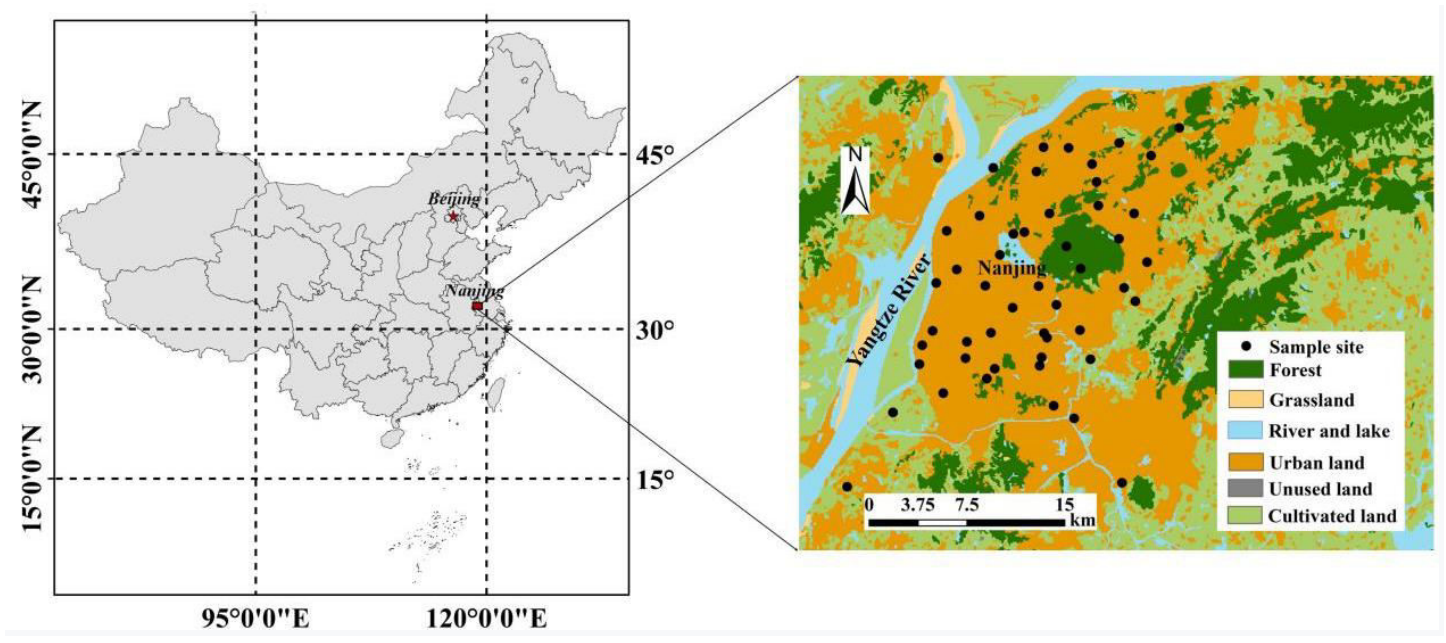

FIG. 1 Distribution of sampling points.

\subsubsection{Principal component analysis}

The factor analysis program in IBM SPSS Statistics 26 software was used to conduct principal component analysis on the original data after standardized processing. The purpose of principal component analysis is to describe the relationship between a variety of indicators or factors with a small number of factors. [10]

\subsubsection{Evaluation of soil heavy metal pollution}

The geoaccumulation index, single factor pollution index and Nemerow pollution index were used to comprehensively evaluate the degree of heavy metal pollution in the soil in Nanjing. German scientist Muller ${ }^{[1]}$ proposed the 
geoaccumulation index method in 1969. He utilized the measured heavy metal content in the geochemical background value as the parameter. The heavy metals in the soil were classified into different levels according to the calculated ground accumulation index. The formula is as follows:

$$
I_{g e o}=\log _{2} \frac{C_{i}}{k \times B_{i}}
$$

where $I_{g e o}$ is the cumulative index of the ground, $\mathrm{Ci}$ is the content of heavy metals in the measured soil samples, and $\mathrm{Bi}$ is the geochemical background value. $\mathrm{K}$ is the correction factor, usually 1.5. According to $I_{g e o}$, there are seven levels of pollution (Table 1).

Table 1 Classification of cumulative index pollution

\begin{tabular}{ccc}
\hline$I_{\text {geo }}$ & Pollution degree & Pollution level \\
\hline$\leq 0$ & 0 & No pollution \\
$0 \sim 1$ & 1 & Light pollution \\
$1 \sim 2$ & 2 & Moderate pollution \\
$2 \sim 3$ & 3 & Moderate pollution - high pollution \\
$3 \sim 4$ & 4 & Strong pollution \\
$4 \sim 5$ & 5 & Heavy pollution - extremely high \\
& & pollution \\
\hline
\end{tabular}

The single factor pollution index method directly reflects the cumulative degree of pollution of a certain heavy metal in the soil ${ }^{[12]}$. The formula is as follows:

$$
P_{i}=C_{i} / S_{i}
$$

where $P_{i}$ is the single factor pollution index of an element in the soil, $C_{i}$ is the measured concentration of an element, and $S_{i}$ is the evaluation standard of a heavy metal element. In this paper, the Nanjing soil background value is selected as the evaluation standard [13]. The Nemerow pollution index method can reflect the 
average pollution degree and environmental quality of heavy metals in the soil ${ }^{[14]}$ to evaluate the impact of pollutants on the soil. The formula is:

$$
P=\sqrt{\frac{\left(\bar{P}_{l}\right)^{2}+\left(P_{\text {imax }}\right)^{2}}{2}}
$$

where $P$ is the Nemerow pollution index of soil heavy metal elements, $\bar{P}_{l}$ is the average value of the single factor pollution index of an element, and $P_{\text {imax }}$ is the maximum value of the single factor pollution index of an element. The ratings are as follows (Table 2).

Table 2 Soil heavy metal pollution classification standards

\begin{tabular}{|c|c|c|c|c|c|}
\hline Hierarchy & I & II & III & IV & $\mathrm{V}$ \\
\hline \multicolumn{6}{|l|}{ Single factor } \\
\hline & $\mathrm{P}_{\mathrm{i}} \leq 0.7$ & $0.7<\mathrm{P}_{\mathrm{i}} \leq 1$ & $1<\mathrm{P}_{\mathrm{i}} \leq 2$ & $2<\mathrm{P}_{\mathrm{i}} \leq 3$ & $\mathrm{P}_{\mathrm{i}} \geq 3$ \\
\hline \multicolumn{6}{|l|}{ pollution index $\left(\mathrm{P}_{\mathrm{i}}\right)$} \\
\hline & $\mathrm{P} \leq 0.7$ & $0.7<\mathrm{P} \leq 1$ & $1<\mathrm{P} \leq 2$ & $2<\mathrm{P} \leq 3$ & $\mathrm{P} \geq 3$ \\
\hline \multicolumn{6}{|l|}{ inde $x(P)$} \\
\hline & & & & Moderate & Heavy \\
\hline Pollution levels & & & & pollution & pollution \\
\hline
\end{tabular}

\subsubsection{Potential ecological risk index}

In this study, the Hakanson potential ecological risk index method ${ }^{[15]}$ was adopted to evaluate the risk degree of heavy metals in the soil in Nanjing. This method combines ecology, biochemistry and other aspects to evaluate the potential ecological risk from heavy metals. The formula is as follows:

$$
\begin{gathered}
C_{f}^{i}=\frac{C^{i}}{C_{n}^{i}} \\
E_{r}^{i}=T_{r}^{i} \times C_{f}^{i} \\
R I=\sum_{i=1}^{m} E_{r}^{i}
\end{gathered}
$$

where $C_{f}^{i}$ is the pollution coefficient of a single heavy metal; $C^{i}$ is the content of heavy metals in the samples measured experimentally; and $C_{n}^{i}$ is the reference ratio 
of heavy metal pollutant $i$. In this study, the Nanjing soil background value ${ }^{[10]}$ was used as the reference ratio, $T_{r}^{i}$ is the corresponding toxicity coefficient of pollutant $\mathrm{i}$, and the toxicity coefficient of each heavy metal is $\mathrm{Cd}=30, \mathrm{Cu}=\mathrm{Ni}=\mathrm{Pb}=5, \mathrm{Cr}=2$, and $\mathrm{Ti}=\mathrm{Zn}=\mathrm{Mn}=1^{[16 \sim 17]}$.

$E_{r}^{i}$ is the potential ecological risk index of a single heavy metal element $\mathrm{i}$, and $\mathrm{RI}$ is the comprehensive potential ecological risk index of various heavy metals in the study area. The Hakanson method delineates the scope of RI and determines the specific pollution levels as follows (Table 3).

Table 3 Potential ecological risk levels using the Hakanson method

\begin{tabular}{cccccc}
\hline The degree & Minor & Medium & Strong & Very strong & Extremely \\
of risk & ecological risk & ecological risk & ecological risk & ecological risk & ecological risk \\
\hline$E_{r}^{i}$ & $E_{r}^{i<40}$ & $40 \leq E_{r}^{i}<80$ & $80 \leq E_{r}^{i<160}$ & $160 \leq E_{r}^{i}<320$ & $E_{r}^{i>320}$ \\
$R I$ & $R I<150$ & $150 \leq R I<300$ & $300 \leq R I<600$ & $R \geq 600$ & \\
\hline
\end{tabular}

\subsection{Health risk assessment methods}

Yushan Wang et al. ${ }^{[18]}$, based on the USEPA health risk assessment model ${ }^{[19]}$, utilized formulas and parameters based on soil particles ingested via the mouth, skin contact and breathing, using the three aspects of soil particles, to calculate for three groups of people (adult men, adult women and children) the exposure pathways and exposure levels of a single heavy metal in the soil particles. Then, the non-carcinogenic risk of individual heavy metals was calculated, analysed and evaluated.

\section{Results and analysis}

\subsection{Descriptive statistics of heavy metal content in Nanjing soil}

The descriptive statistics of heavy metals in the study area in Nanjing city in this study are shown in Table 4 . The results show that the average contents of $\mathrm{Cd}, \mathrm{Cr}$, $\mathrm{Cu}, \mathrm{Mn}, \mathrm{Ni}, \mathrm{Pb}, \mathrm{Ti}$ and $\mathrm{Zn}$ were 0.12, 72.39, 36.77, 683.03, 32.64, 32.66, 4648.46, and $109.82 \mathrm{mg} / \mathrm{kg}$, respectively, which were 1.39 times the corresponding soil 
background values in Nanjing. The average contents of $\mathrm{Cu}, \mathrm{Mn}, \mathrm{Pb}$ and $\mathrm{Ti}$ heavy metals in the soil samples were higher than those of the Nanjing soil background values. The over-standard rates of $\mathrm{Mn}, \mathrm{Pb}$ and $\mathrm{Zn}$ were $54.00 \%, 64.00 \%$ and $76.00 \%$, respectively. This indicates that $\mathrm{Mn}, \mathrm{Pb}, \mathrm{Zn}$ and other heavy metals were enriched in the study area in Nanjing.

The coefficient of variation can reflect the difference in variation of soil heavy metal contents at different sampling points, the deviation at different points and their influence on human daily life or industry ${ }^{[20]}$. As seen in Table 1, the coefficient of variations were ranked as $\mathrm{Pb}>\mathrm{Cu}>\mathrm{Zn}>\mathrm{Mn}>\mathrm{Cd}>\mathrm{Ni}>\mathrm{Cr}>\mathrm{Ti}$, among which $\mathrm{Ti}, \mathrm{Cr}, \mathrm{Ni}$ and $\mathrm{Cd}$ all had relatively small coefficients of variation, with values between $10 \%$ and $20 \%$, indicating that these elements were relatively evenly distributed in the study area ${ }^{[21]}$. The variation coefficients of $\mathrm{Pb}$ and $\mathrm{Cu}$ were $67.96 \%$ and $59.76 \%$, respectively, indicating that the distribution of $\mathrm{Pb}$ and $\mathrm{Cu}$ in the study area fluctuated greatly and was subject to great human disturbance.

The above analysis shows that the pollution problem of $\mathrm{Cd}, \mathrm{Cr}, \mathrm{Ni}$ and $\mathrm{Ti}$ was not obvious in the study area in Nanjing. The mean value of the heavy metal content of Mn was slightly higher than the mean value, and the coefficient of variation was slightly higher, which requires more attention. The point over-standard rate and variation coefficient of $\mathrm{Pb}$ in the soil samples were relatively large and should be given more attention.

Table 4 Descriptive statistics of heavy metal content in soil in Nanjing city

\begin{tabular}{|c|c|c|c|c|c|c|c|c|}
\hline Sample & $\mathrm{Cd}$ & $\mathrm{Cr}$ & $\mathrm{Cu}$ & $\mathrm{Mn}$ & $\mathrm{Ni}$ & $\mathrm{Pb}$ & $\mathrm{Ti}$ & $\mathrm{Zn}$ \\
\hline Average/ (mg/kg) & 0.12 & 72.39 & 36.77 & 683.03 & 32.64 & 32.66 & 4648.46 & 109.82 \\
\hline \multicolumn{9}{|l|}{ Standard } \\
\hline deviation/(mg/kg) & 0.02 & 8.50 & 23.92 & 202.26 & 5.43 & 22.19 & 454.94 & 65.63 \\
\hline Maximum/(mg/kg) & 0.17 & 97.49 & 168.04 & 1922.79 & 55.74 & 152.44 & 5427.34 & 466.83 \\
\hline Minimum/( mg/kg) & 0.07 & 48.88 & 9.78 & 417.78 & 20.52 & 13.01 & 3110.97 & 43.12 \\
\hline Coefficient of & 17.06 & 11.74 & 65.06 & 29.61 & 16.63 & 67.96 & 9.79 & 59.76 \\
\hline
\end{tabular}




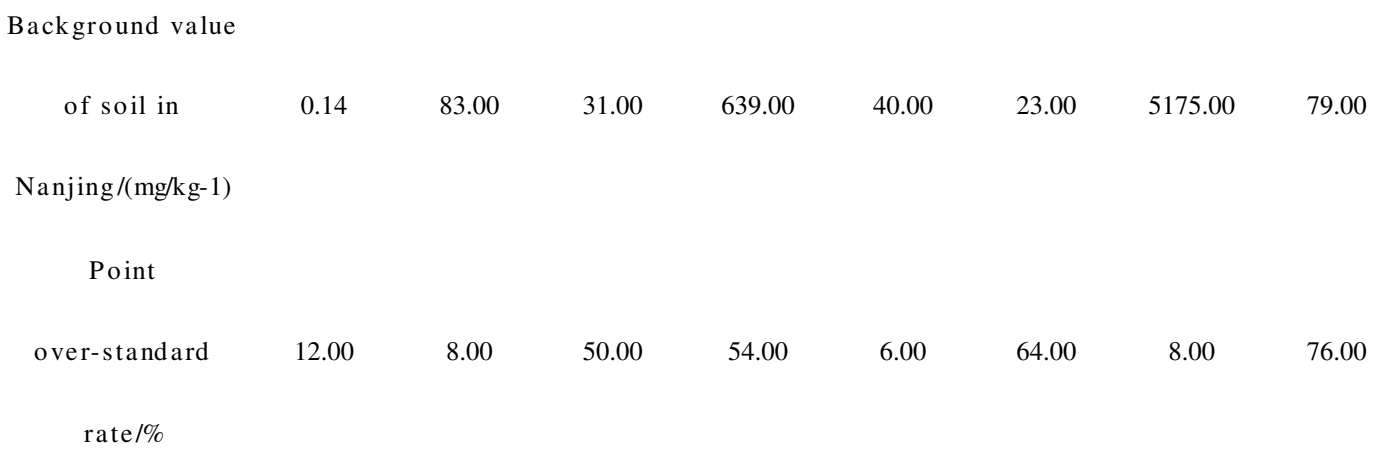

\subsection{Spatial distribution characteristics of heavy metals in soil}

ArcGIS10.0 software was used to perform inverse distance interpolation analysis on the content of all heavy metals (Fig. 2).

According to Fig. 2, $\mathrm{Al}, \mathrm{Cd}$ and $\mathrm{Cr}$ had similar spatial distribution characteristics,: heavy metals were on the high side in the central and western parts of the study area, and the spatial distribution characteristics of $\mathrm{Cu}, \mathrm{Pb}$ and $\mathrm{Zn}$ were similar. The higher concentration was mainly distributed in the middle part of the study area. In general, the concentrations of $\mathrm{Al}, \mathrm{Cd}$ and $\mathrm{Cr}$ were higher than those of $\mathrm{Cu}, \mathrm{Pb}$ and $\mathrm{Zn}$. The high value areas of heavy metals were mainly distributed in the central and western regions, showing a patch-like distribution and decreasing trend from west to east.

Central China is densely populated, railway stations and subway stations are concentrated, and energy consumption and sewage gas discharge are large, which have led to a high content of heavy metals in the soil in the central and some western regions. 

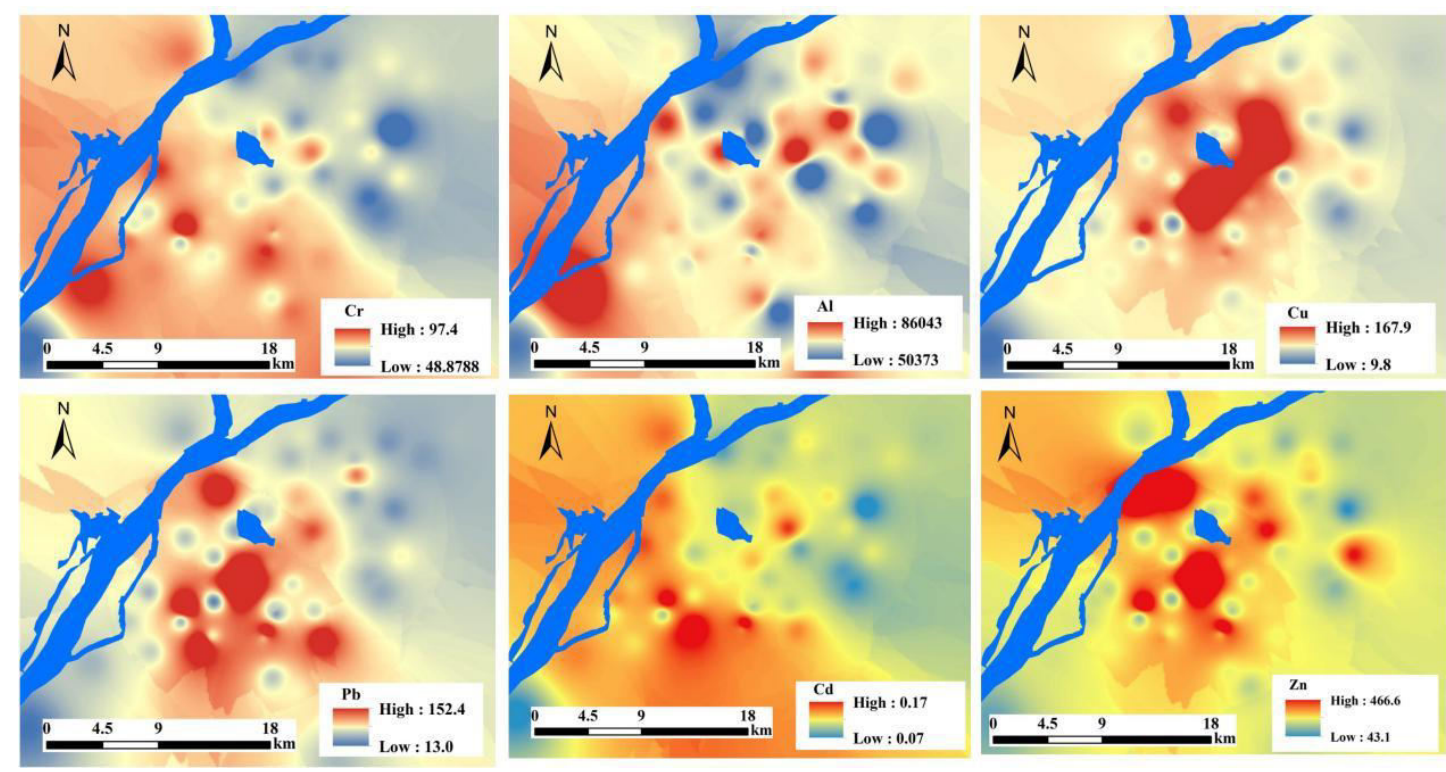

FIG. 2 Spatial distribution of heavy metals in soils in Nanjing.

\subsection{Principal component analysis}

The factor analysis program in IBM SPSS Statistics 26 software was used to conduct principal component analysis after the standardized processing of the original data. The purpose of principal component analysis is to explain the phenomena in terms of major factors. In principal component analysis, correlation analysis of the original variables is required ${ }^{[22]}$. As shown in Table 5, the correlation coefficient matrix among 12 variables was calculated, and Pearson correlation among elements was analysed.

\subsubsection{Correlation analysis}

The results showed (Table 5) that at the 0.01 level (double tailed), the contents of $\mathrm{Cd}, \mathrm{Cr}, \mathrm{Fe}, \mathrm{Ni}$ and $\mathrm{Al} ; \mathrm{Cu}, \mathrm{Mg}, \mathrm{Pb}, \mathrm{Zn}$ and $\mathrm{Ca} ; \mathrm{Cr}, \mathrm{Fe}, \mathrm{Ni}$ and $\mathrm{Cd} ; \mathrm{Fe}, \mathrm{Ni}$, Ti and $\mathrm{Cr} ; \mathrm{Pb}, \mathrm{Zn}$ and $\mathrm{Cu} ; \mathrm{Ni}, \mathrm{Ti}$ and $\mathrm{Fe}$; and $\mathrm{Zn}$ and $\mathrm{Pb}$ showed a significant correlation, indicating that each of the se elements within the same grouping has the same tendency to change as the other elements in the same grouping and that they may have the same source. Ti and $\mathrm{Ca}$; $\mathrm{Ti}$ and $\mathrm{Cu}$; and $\mathrm{Pb}$ and $\mathrm{Zn}$ show opposite changes, indicating that their concentrations are inversely related. At the 0.05 level (double tailed), the contents of $\mathrm{Ni}$ and $\mathrm{Mn}$; $\mathrm{Pb}, \mathrm{Ti}, \mathrm{Zn}$ and $\mathrm{Cd}$; and $\mathrm{Al}, \mathrm{Ni}, \mathrm{Cd}$ and $\mathrm{Ti}$ are significantly correlated, and they may have come from the same source. 
Table 5 Correlation of heavy metal elements

\begin{tabular}{|c|c|c|c|c|c|c|c|c|c|c|c|c|}
\hline & $\mathrm{Al}$ & $\mathrm{Ca}$ & $\mathrm{Cd}$ & $\mathrm{Cr}$ & $\mathrm{Cu}$ & $\mathrm{Fe}$ & $\mathrm{Mg}$ & $\mathrm{Mn}$ & $\mathrm{Ni}$ & $\mathrm{Pb}$ & $\mathrm{Ti}$ & $\mathrm{Zn}$ \\
\hline $\mathrm{Al}$ & 1 & -0.006 & $0.475^{* *}$ & $0.461^{* * *}$ & 0.099 & $0.655^{* *}$ & -0.004 & -0.015 & $0.431^{* *}$ & -0.115 & $0.310^{*}$ & 0.002 \\
\hline $\mathrm{Ca}$ & & 1 & 0.21 & 0.032 & $0.427^{* *}$ & -0.061 & $0.621^{* *}$ & -0.042 & -0.081 & $0.465^{* *}$ & $-0.652^{* *}$ & $0.493^{* *}$ \\
\hline $\mathrm{Cd}$ & & & 1 & $0.699^{* *}$ & 0.258 & $0.770^{* *}$ & 0.041 & 0.061 & $0.528^{* *}$ & $0.348^{*}$ & $0.286^{*}$ & $0.315^{*}$ \\
\hline $\mathrm{Cr}$ & & & & 1 & 0.139 & $0.721^{* *}$ & 0.054 & 0.109 & $0.683^{* *}$ & 0.214 & $0.489^{* *}$ & 0.216 \\
\hline $\mathrm{Cu}$ & & & & & 1 & 0.21 & 0.029 & 0.097 & 0.274 & $0.827^{* *}$ & $-0.438^{* *}$ & $0.869^{* *}$ \\
\hline $\mathrm{Fe}$ & & & & & & 1 & -0.034 & 0.037 & $0.527^{* *}$ & 0.135 & $0.537^{* *}$ & 0.149 \\
\hline $\mathrm{Mg}$ & & & & & & & 1 & -0.084 & -0.077 & -0.014 & -0.238 & 0.022 \\
\hline $\mathrm{Mn}$ & & & & & & & & 1 & $0.292^{*}$ & 0.116 & 0.168 & 0.098 \\
\hline $\mathrm{Ni}$ & & & & & & & & & 1 & 0.221 & $0.298^{*}$ & 0.26 \\
\hline $\mathrm{Pb}$ & & & & & & & & & & 1 & $-0.454^{* *}$ & $0.915^{* *}$ \\
\hline $\mathrm{Ti}$ & & & & & & & & & & & 1 & $-0.468^{* * *}$ \\
\hline $\mathrm{Zn}$ & & & & & & & & & & & & 1 \\
\hline
\end{tabular}

Note: "**." indicates a significant correlation at the level of 0.01 (double tailed). "*." indicates a significant correlation at the level of 0.05 (double tailed).

\subsubsection{Principal component analysis}

According to the results of the principal component analysis, four effective principal factors were extracted, which were $\mathrm{Al}, \mathrm{Ca}, \mathrm{Cd}$ and $\mathrm{Cr}$, and their variance contributions accounted for $33 \%, 28 \%, 13 \%$ and $8 \%$ of the total variance, respectively. From the component matrix in Table 6, we can see how much information reflecting an element is extracted by the principal component. The principal component can be expressed as a linear combination of each element:

The first principal component:

$0.520 \mathrm{Z} \mathrm{Al}+0.317 \mathrm{Z} \mathrm{Ca}+0.815 \mathrm{Z} \mathrm{Cd}+0.764 \mathrm{Z} \mathrm{Cr}+0.645 \mathrm{Z} \mathrm{Cu}+0.752 \mathrm{Z} \times \times 10+0.058 Z \mathrm{Mg}+0.187 \mathrm{Z}$

$\mathrm{Mn}+0.707 \mathrm{Z} \mathrm{Ni}+0.637 \mathrm{Z} \mathrm{Pb}+0.104 \mathrm{Z} \mathrm{Ti}+0.664 \mathrm{ZZn}$

The second principal component:

$0.451 Z A 1-0.689 \mathrm{ZCa}+0.245 \mathrm{ZCd}+0.423 \mathrm{ZCr}-0.601 \mathrm{ZCu}+0.499 \mathrm{ZF} \times 10-0.286 \mathrm{ZMg}+0.073 \mathrm{ZMn}+0.322$

ZNi-0.649ZPb+0.909ZTi-0.650ZZn 
The third principal component:

$0.277 \mathrm{ZAl}+0.542 \mathrm{ZCa}+0.179 \mathrm{ZCd}+0.121 \mathrm{ZCr}-0.238 \mathrm{ZCu}+0.135 \mathrm{ZF} \times 10+0.810 \mathrm{ZMg}-0.419 \mathrm{ZMn}-0.163$

ZNi-0.289ZPb-0.095ZTi-0.243ZZn

The fourth principal component:

$-0.189 \mathrm{ZAl}+0.173 \mathrm{ZCa}-0.070 \mathrm{ZCd}+0.080 \mathrm{ZCr}-0.120 \mathrm{ZCu}-0.162 \mathrm{ZF} \times 10+0.375 \mathrm{ZMg}+0.830 \mathrm{ZMn}+0.22$ 0ZNi-0.069ZPb+0.077ZTi-0.087ZZn

It can be seen from (1), (2), (3) and (4) that the contents of heavy metal elements $\mathrm{Cd}, \mathrm{Cr}, \mathrm{Fe}$ and $\mathrm{Ni}$ in the first principal component contributed greatly, and this pollution may have come from industrial wastewater from mines and smelting. Therefore, the first principal component was determined to be an industrial pollution source. The contents of $\mathrm{Ti}$ and $\mathrm{Fe}$ in the second principal component contributed greatly, and these elements were labelled characteristic elements of the soil parent material. Therefore, the second principal component was determined to be the source of parent material ${ }^{[10]} . \mathrm{Mg}$ and $\mathrm{Ca}$ contributed more to the third principal component, which are the main components of common fertilizers, and the third principal component was determined as the source of fertilizers ${ }^{[22]}$. Mn and $\mathrm{Mg}$ contributed more to the fourth principal component, and these two elements represent precipitation and a combination of processes of $\mathrm{Fe}$ and $\mathrm{Mn}$ in the soil-weathering process ${ }^{[22]}$. Therefore, the fourth principal component was judged as the weathering and deposition source. The element distribution is regional, and the main heavy metal elements in different regions are different. According to the principal component analysis, the industrial contribution of heavy metals in Nanjing soil was the largest, reaching $34.4 \%$. The parent material and fertilizer sources contributed $32.3 \%$ and $19.6 \%$, respectively, and the weathering and deposition sources contributed $13.7 \%$.

Table 6 Component matrix ${ }^{a}$

\begin{tabular}{ccccc}
\hline & \multicolumn{3}{c}{ Composition } \\
Element & 1 & 2 & 3 & 4 \\
\hline Al & 0.52 & 0.451 & 0.277 & -0.189
\end{tabular}




\begin{tabular}{ccccc}
$\mathrm{Ca}$ & 0.317 & -0.689 & 0.542 & 0.173 \\
$\mathrm{Cd}$ & 0.815 & 0.245 & 0.179 & -0.07 \\
$\mathrm{Cr}$ & 0.423 & 0.121 & 0.08 \\
$\mathrm{Cu}$ & -0.601 & -0.238 & -0.12 \\
$\mathrm{Fe}$ & 0.645 & 0.499 & 0.135 & -0.162 \\
$\mathrm{Mg}$ & 0.752 & -0.286 & 0.81 & 0.375 \\
$\mathrm{Mn}$ & 0.058 & 0.073 & -0.419 & 0.83 \\
$\mathrm{Ni}$ & 0.187 & 0.322 & -0.163 & 0.22 \\
$\mathrm{~Pb}$ & 0.707 & -0.649 & -0.289 & -0.069 \\
$\mathrm{Ti}$ & 0.637 & 0.909 & -0.095 & 0.077 \\
$\mathrm{Zn}$ & 0.104 & -0.65 & -0.243 & -0.087 \\
\hline
\end{tabular}

a. Four components were extracted.

Table 5 Total variance interpretation

\begin{tabular}{|c|c|c|c|c|c|c|}
\hline \multirow[b]{3}{*}{ Composition } & \multicolumn{3}{|c|}{ Initial eigenvalue } & \multicolumn{3}{|c|}{ Sum of squares of the extraction load } \\
\hline & \multicolumn{3}{|c|}{ Percentage of } & \multicolumn{3}{|c|}{ Percentage of } \\
\hline & Total & variance & Cumulative $\%$ & Total & variance & Cumulative $\%$ \\
\hline 1 & 3.995 & 33.29 & 33.29 & 3.995 & 33.29 & 33.29 \\
\hline 2 & 3.389 & 28.242 & 61.531 & 3.389 & 28.242 & 61.531 \\
\hline 3 & 1.502 & 12.518 & 74.049 & 1.502 & 12.518 & 74.049 \\
\hline 4 & 1.014 & 8.449 & 82.498 & 1.014 & 8.449 & 82.498 \\
\hline 5 & 0.649 & 5.406 & 87.904 & & & \\
\hline 6 & 0.502 & 4.18 & 92.084 & & & \\
\hline 7 & 0.367 & 3.061 & 95.145 & & & \\
\hline 8 & 0.231 & 1.927 & 97.072 & & & \\
\hline 9 & 0.127 & 1.057 & 98.129 & & & \\
\hline 10 & 0.09 & 0.747 & 98.876 & & & \\
\hline 11 & 0.077 & 0.643 & 99.519 & & & \\
\hline 12 & 0.058 & 0.481 & 100 & & & \\
\hline
\end{tabular}


The pollution index of each heavy metal was calculated based on the soil background value of Nanjing that was used as the evaluation standard. From the perspective of the single factor pollution index, the average value of the single factor pollution index of $\mathrm{Cd}$ was 0.83 , which was the lowest among the five heavy metals, representing a clean soil in regard to $\mathrm{Cd}$. The average value of the $\mathrm{Cr}$ single factor pollution index was 0.88 , indicating light pollution. The average value of the $\mathrm{Cu}$ single factor pollution index was 1.19 , which represents light pollution. The maximum value was 5.42 , far greater than 3 , which indicates heavy pollution. The minimum value was 0.32 , which was lower than the minimum values of $\mathrm{Cd}$ and $\mathrm{Cr}$ and indicates no pollution. The average value of the single factor pollution index of $\mathrm{Pb}$ was 1.42 , which was the highest among the five heavy metals, which indicates light pollution; the maximum value was 6.63 , representing heavy pollution, which was also the maximum value of a single factor pollution index of all heavy metals; and the minimum value was 0.56 , indicating a clean soil in regard to $\mathrm{Pb}$. There were also differences between $\mathrm{Pb}$ heavy metals in different regions in Nanjing. The average value of the $\mathrm{Zn}$ single factor pollution index was 1.39, indicating light pollution; the maximum value was 5.91, indicating heavy pollution; and the minimum value was 0.54 , indicating a clean level. In terms of the average value of the single factor pollution index, the pollution degree of different heavy metals was ranked as $\mathrm{Pb}>\mathrm{Zn}>\mathrm{Cu}>\mathrm{Cr}>\mathrm{Cd}$, indicating that $\mathrm{Pb}$ was the most serious heavy metal polluting element in Nanjing. Pb pollution can cause serious harm to the soil, human body, crops and economy. Therefore, Nanjing should give attention to the $\mathrm{Pb}$ metal pollution.

According to the Nemerow pollution index of each heavy metal, the pollution index of different heavy metals ranged from 0.9 to 5 . The pollution degree of each heavy metal varied greatly in Nanjing, indicating different pollution degrees. The highest pollution level was $\mathrm{Pb}$, its Nemerow pollution index was 4.79 , which indicates heavy pollution. The lowest pollution level was Ti, and its Nemerow pollution index was 0.98 , which indicates a clean level. Among all heavy metals, $\mathrm{Cu}$, $\mathrm{Pb}$ and $\mathrm{Zn}$ indicate a heavy polluted; $\mathrm{Mn}$ indicates a moderately polluted level; and 
$\mathrm{Cd}, \mathrm{Cr}$ and $\mathrm{Ni}$ indicate a mildly polluted level. According to the Nemerow pollution index of each heavy metal, the pollution degree in the Nanjing area was ranked as $\mathrm{Pb}>\mathrm{Zn}>\mathrm{Cu}>\mathrm{Mn}>\mathrm{Ni}>\mathrm{Cd}=\mathrm{Cr}>\mathrm{Ti}$.

According to the average single potential risk index of heavy metals, the potential ecological risks of the eight heavy metals in the Nanjing research area were ranked as $\mathrm{Cd}>\mathrm{Pb}>\mathrm{Cu}>\mathrm{Ni}>\mathrm{Cr}>\mathrm{Zn}>\mathrm{Mn}>\mathrm{Ti}$. The average single potential risk indices were $24.86,7.10,5.93,4.08,1.74,1.39,1.07$, and 0.90 , respectively, indicating slight ecological risk. The Ti single potential ecological risk index was less than 1 , indicating the least degree of harm. The average $\mathrm{Cd}$ single potential risk index was 24.86 , which was the most harmful but it had only a slight ecological risk, indicating that $\mathrm{Cd}$ was the most important ecological risk element in the Nanjing research area. In conclusion, the comprehensive potential ecological risk index was 47.07, which is above 40, reaching the level of medium potential ecological risk, which should be given more attention, and measures should be formulated to prevent the further aggravation of heavy metal soil pollution, especially the treatment of $\mathrm{Cd}$ heavy metal pollution.

Table 8 Each ecological risk index

Individual potential

ir)

\begin{tabular}{|c|c|c|c|c|c|c|c|}
\hline & \multirow{5}{*}{ Pollution index } & \multirow{2}{*}{\multicolumn{2}{|c|}{ hierarch }} & \multirow{3}{*}{ Maximu } & \multirow{3}{*}{ Minimum } & \multirow{2}{*}{\multicolumn{2}{|c|}{ Risk }} \\
\hline & & & & & & & \\
\hline & & & Average & & & Risk inde $\mathrm{x}$ & classificatio \\
\hline & & $\mathrm{y}$ & & $\mathrm{m}$ & value & & \\
\hline & & & & & & & $\mathrm{n}$ \\
\hline $\mathrm{Cd}$ & 1.036538764 & mild & 0.83 & 1.21 & 0.53 & 24.86 & slight \\
\hline $\mathrm{Cr}$ & 1.034446001 & mild & 1 & 1 & 1 & 1.74 & slight \\
\hline $\mathrm{Cu}$ & 3.92367681 & severe & 1 & 5 & 0 & 5.93 & slight \\
\hline Mn & 2.25798651 & moderate & & & & 1.07 & slight \\
\hline $\mathrm{Ni}$ & 1.141838431 & mild & & & & 4.08 & slight \\
\hline $\mathrm{Pb}$ & 4.792824096 & severe & 1.42 & 6.63 & 0.56 & 7.1 & slight \\
\hline
\end{tabular}




\begin{tabular}{|c|c|c|c|c|c|c|c|}
\hline $\mathrm{Ti}$ & 0.97641134 & clean & & & & 0.9 & slight \\
\hline $\mathrm{Zn}$ & 4.2925241 & severe & 1.39 & 5.91 & 0.54 & 1.39 & slight \\
\hline \multicolumn{8}{|c|}{ comprehensiv } \\
\hline $\mathrm{e}$ & & & & & & & \\
\hline
\end{tabular}

3.5 Health risk assessment of heavy metals in Nanjing soil

The concentration of heavy metals in 50 soil samples collected in Nanjing in this study was processed according to the USEPA health risk assessment model ${ }^{[15]}$, and the exposure amount of a single heavy metal in the soil particle exposure pathway under the non-carcinogenic risk was obtained, as well as the results of its non-carcinogenic risk (Table 9).

According to the data in Table 9, the exposure amount of a single heavy metal in the exposure pathway of soil particles under three non-carcinogenic risks was analysed. Through the overall analysis of the average exposure amount and the analysis of oral intake exposure amount, except for $\mathrm{Cd}$, the exposure amount was ranked as children > adult female > adult male. Skin contact exposure was analysed, except for $\mathrm{Cu}$ element, and the exposure was ranked as children > adult female > adult male. Inhaled soil particle exposure was analysed and ranked as children > adult male > adult female. In conclusion, children are exposed to large amounts of soil particles in various ways. Therefore, attention should be given to the health problems from heavy metals in children.

The mean values of the total non-carcinogenic risk (HI) to adult males, adult females and children were $3.14 \times 10^{-6}, 3.25 \times 10^{-6}$, and $6.17 \times 10^{-5}$, respectively, which were the acceptable ranges (HI $<1^{[23]}$ ). The total mean value (HI) of the risk-exposed population was ranked from low to high as adult males, adult females and children. This is consistent with the research results of Yushan Wang et al. ${ }^{[18]}$. Among these three groups of exposed people, the HQ average values of the four heavy metal elements selected in this study were ranked from high to low as $\mathrm{HQ}_{\mathrm{Cu}}>\mathrm{HQ}_{\mathrm{Pb}}>\mathrm{HQ}_{\mathrm{Cd}}>$ $\mathrm{HQ}_{\mathrm{Zn}}$. Among them, the $\mathrm{HI}$ of $\mathrm{Pb}$ to adult males and adult females accounted for $54.29 \%$ and $55.89 \%$, respectively. 
In summary, the aggregate values of the non-carcinogenic risks of $\mathrm{Cd}, \mathrm{Cu}, \mathrm{Pb}$ and $\mathrm{Zn}$ in Nanjing are all within their acceptable ranges at present, and the contribution values of $\mathrm{Pb}$ and $\mathrm{Cu}$ to $\mathrm{HI}$ are relatively high. Therefore, the monitoring and control of $\mathrm{Pb}$ and $\mathrm{Cu}$ should be strengthened.

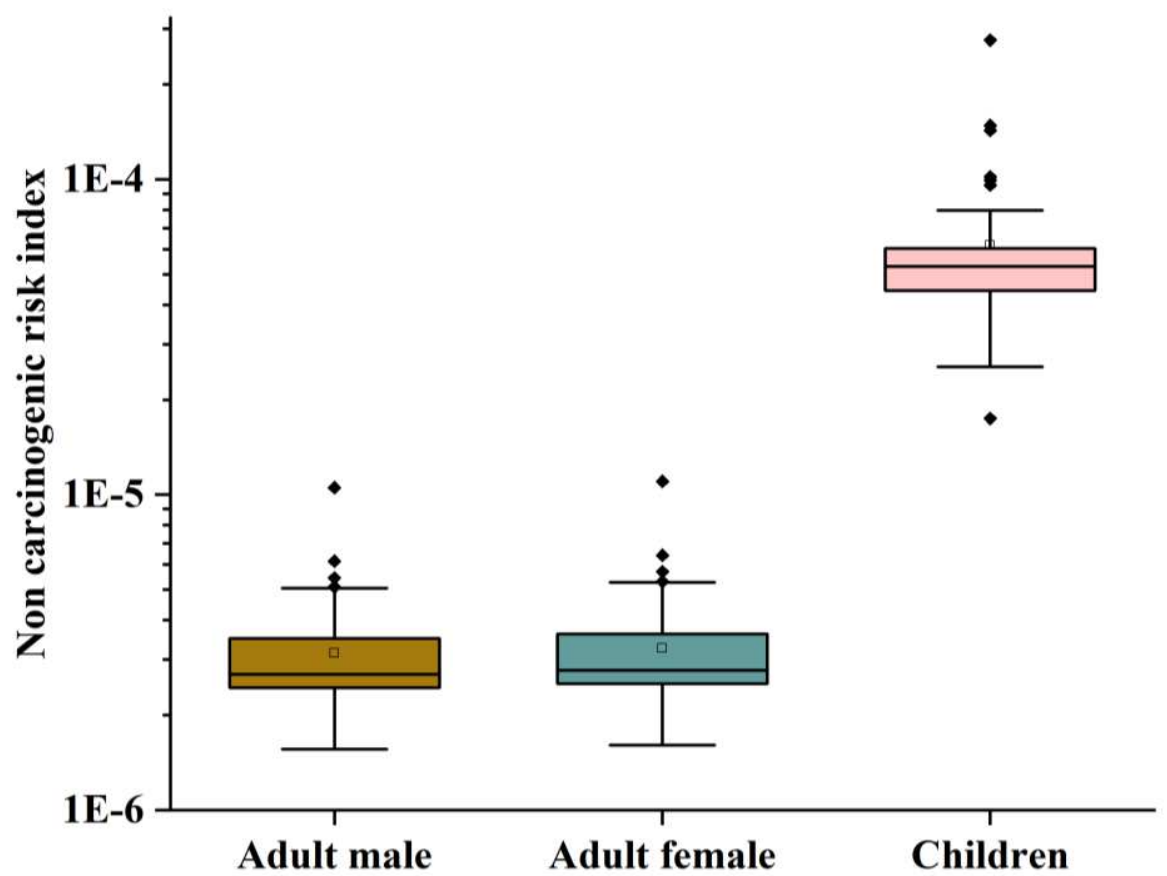

FIG 3 Non-carcinogenic risks (The ordinate is logarithmized).

Table 9 Health risk assessment

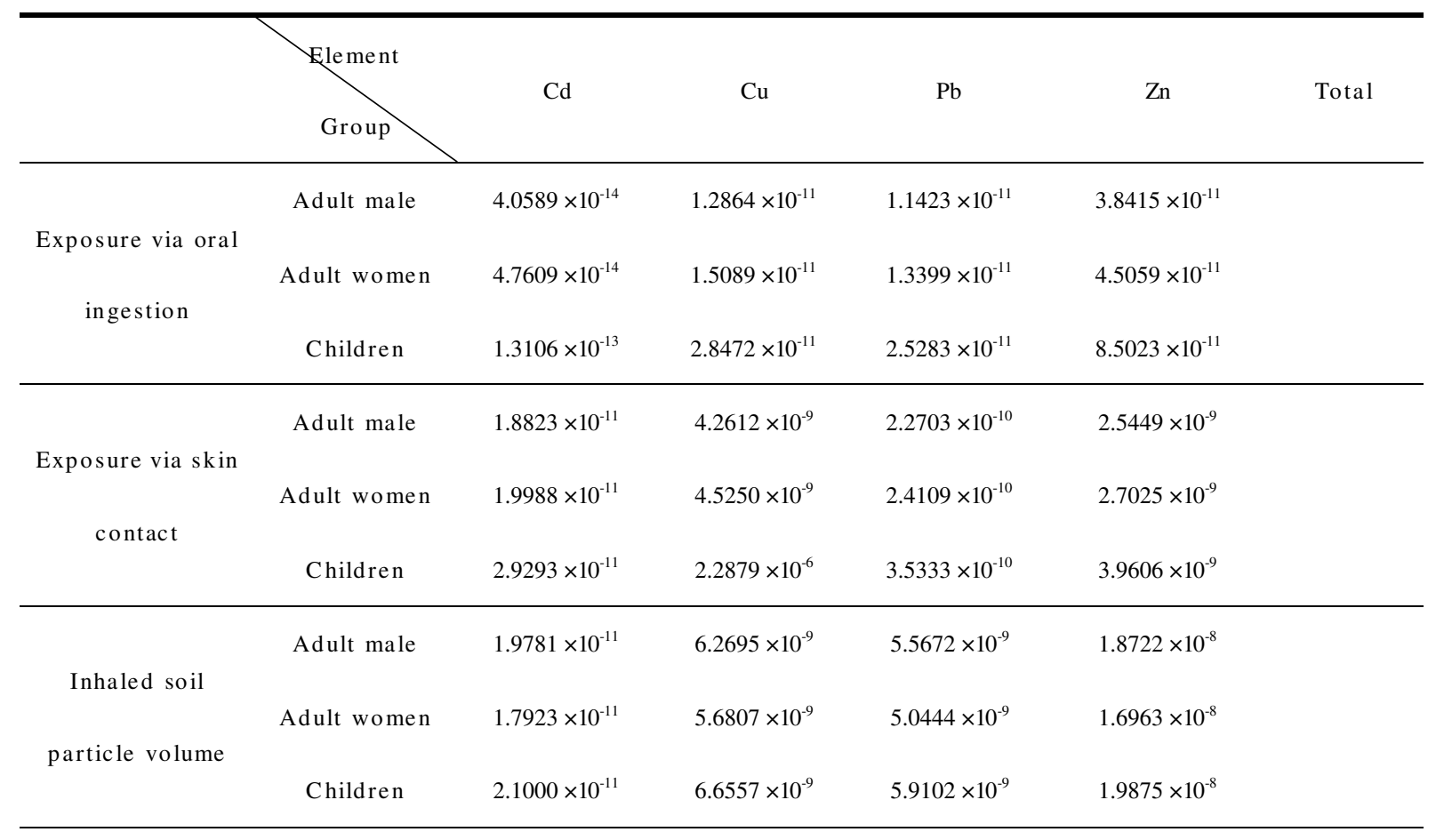




\begin{tabular}{|c|c|c|c|c|c|c|}
\hline & Adult male & $1.10 \times 10^{-6}$ & $2.64 \times 10^{-7}$ & $1.70 \times 10^{-6}$ & $7.10 \times 10^{-8}$ & $3.14 \times 10^{-6}$ \\
\hline Non-carcinogenic & Adult women & $1.11 \times 10^{-6}$ & $2.56 \times 10^{-7}$ & $1.82 \times 10^{-6}$ & $6.57 \times 10^{-8}$ & $3.25 \times 10^{-6}$ \\
\hline \multirow[t]{2}{*}{ risk } & Children & $1.54 \times 10^{-6}$ & $5.74 \times 10^{-5}$ & $2.70 \times 10^{-6}$ & $7.97 \times 10^{-8}$ & $6.17 \times 10^{-5}$ \\
\hline & Total & $3.75 \times 10^{-6}$ & $5.79 \times 10^{-5}$ & $6.23 \times 10^{-6}$ & $2.16 \times 10^{-7}$ & $6.81 \times 10^{-5}$ \\
\hline
\end{tabular}

4 Conclusion

(1) The pollution from $\mathrm{Cd}, \mathrm{Cr}, \mathrm{Ni}$ and $\mathrm{Ti}$ was not found in the study area in Nanjing. The mean heavy metal content of Mn was slightly higher than the background value, and the coefficient of variation was slightly higher, which needs more attention. The point over-standard rate and variation coefficient of $\mathrm{Pb}$ in soil were relatively large and should be given more attention. The results of principal component analysis showed that the contents of $\mathrm{Pb}, \mathrm{Zn}$ and $\mathrm{Cu}$; $\mathrm{Ni}$, Ti and $\mathrm{Fe}$; and $\mathrm{Zn}$ and $\mathrm{Pb}$ were significantly correlated, indicating that they may have the same pollution sources. $\mathrm{Ti}$ and $\mathrm{Ca}, \mathrm{Ti}$ and $\mathrm{Cu}$, and $\mathrm{Pb}$ and $\mathrm{Zn}$ showed opposite changes, indicating that their concentrations were inversely related.

(2) In terms of the average value of the single factor pollution index, the degree of pollution of different heavy metals was ranked as $\mathrm{Pb}>\mathrm{Zn}>\mathrm{Cu}>\mathrm{Cr}>\mathrm{Cd}$, indicating that $\mathrm{Pb}$ was the most serious heavy metal polluting element in Nanjing. Therefore, Nanjing should give more attention to the problem of $\mathrm{Pb}$ metal pollution.

(3) The USEPA health risk assessment model was used to analyse the exposure amount of individual heavy metals in soil particle exposure pathways in adult males, adult females and children. The results showed that the exposure amount of soil particles in each pathway of heavy metals in children was higher, and the non-carcinogenic risk of $\mathrm{Pb}$ and $\mathrm{Cu}$ was higher.

(4) The contribution of soil heavy metals from industrial sources in Nanjing was the largest, reaching $34.4 \%$. The parent material and fertilizer sources contributed $32.3 \%$ and $19.6 \%$, respectively, and the weathering and deposition sources contributed $13.7 \%$. 


\section{References:}

[1]ZHANG Hui, Asfand Shahab. Study on Risk Assessment of Heavy Metal Pollution in Smelter Dust [J]. Metallurgical smelt ing,2019(14):9-10.

[2]JI Wengui, WANG Ke, MENG Jianbo, ZHENG Jinde, ZHOU Linji, ZHAO Huarong. Distribution Characteristics and Risk Assessment of Soil Heavy Metal Pollution in China[J]. Agricultural research and application,2020,33(05):22-28.

[3]YE Mai, ZHANG Jing-ru, ZHANG Lu-lu, LI Zhao-hui, LI Xing-yuan, ZHOU Yong-zhang. Transfer Factor and Health Risk Assessment of Heavy Metals in a Soil-Crop System in a High Incidence Area of Nasopharyngeal Carcinoma, Guangdong [J]. Environmental Science,2020,41(12):5579-5588.

[4]GUO Xing, WANG Yinggang, CAO Xiaoxiao, ZHANG Ting. Effect and Ecological Risk of Urbanization on Heavy Metal Accumulation in Soil of Jinzhong Basin[J]. Bulletin of Soil and Water Conservation,2018,38(02):53-57+64.

[5]HUANG Fei-Fei, WANG Ying, ZHANG Ning. Heavy metal pollution status of local rice and human dietary exposure risk assessment in Suzhou city[J]. Journal of Food Safety and Quality,2020,11(23):9039-9045.

[6]HAN Lin, XU Xi-bo. Quantitative Evaluation of Human Health Risk of Heavy Metals in Soils Based on Positive Matrix Factorization Model and Geo-statistics[J]. Environmental Science,2020,41(11):5114-5124.

[7]CHENG Junwei, CAI Shenwen, HUANG Mingqin. Analysis on Speciation and Risk Assessment of Heavy Metals in Soil and Surface Sediments of Maoshi Molybdenum mining Area in Guizhou [J]. Research of Soil and Water Conservation,2021,28(01):353-359.

[8]WANG Rui, DENG Hai, JIA Zhong-min, WANG Jia-bin ,YU Fei, ZENG Qin-qin. Spatial Distribution Characteristics, Pollution, and Ecological Risk Assessment of Soil Heavy Metals Around Mercury Mining Areas [J/OL]. Environmental Science:1-13[2021-01-01].

[9]CHEN Jia-lin, LI Ren-ying, XIE Xiao-jin, WANG Hong, XU Jing, SHAO Jing, JIAN Jing, Akejuli-Wuerman, SHEN Jia, YANG Zong. Distribution Characteristics and Pollution Evaluation of Heavy Metals in Greenbelt Soils of Nanjing City [J/OL]. Environmental Science:1-12[2021-01-01].

[10]Ma Tingjun, Lin Bingrong, Jia Changxi. Reclaimed Water Heavy Metal Residues Cluster Analysis and Principal Component Analysis[J]. Chinese Agricultural Science Bullet in,2010,26(24):318-321.

[11]Muller G . Index of Geoaccumulation in Sediments of the Rhine River[J]. GeoJournal, 1969, 2(3):109-118.

[12]ZHANG Peng-yan, QIN Ming-zhou, CHEN Long, HU Chang-hui, ZHAO Ya-ping, DONG Wei-jun. Study on Distribution Characteristics and Potential Ecological R isk of Soil Heavy Metals in the Yellow River Beach Region in Kaifeng City[J]. Environmental Science,2013,34(09):3654-3662.

[13]CHENG Hangxin, LI Kuo, LI Min, et al. Geochemical background and baseline value of chemical elements in urban soil in China.Earth Science Frontiers, 2014, 21(3):265-306.

[14]ZHOU Qin-li, WANG Xue-dong, LI Zhi-tao, WANG Xia-hui, HE Jun, JI Guo-hua. Distribution characteristics and ecological risk assessment of soil heavy metal in Helan County of Ningxia,China. [J]. Journal of Agricultural Resources and Environment,2019,36(04):513-521.

[15]Hakanson L. An ecological risk index for aquatic pollution control.a sedimentological approach[J]. Water Research, 1980.

[16]HU Guojian, CHEN Chuanming, GUO Lianchao, HOU Yufeng. The Effects of Ecological Compensation on Livelihood Capital and Correlation of Rural Residents in Nature Reserve: Taking Minjiangyuan National Nature Reserve in Fujian as an Example[J]. Ecological Economy,2018,34(08):145-149+155.

[17]Xu Zheng- qi, Ni Shi- jun, Tuo Xian- guo, Zhang Cheng- jiang. Calculation of Heavy Metals ' Toxicity Coefficient in the Evaluation of Potential Ecological Risk Index[J]. Environmental Science \& Technology,2008(02):112-115.

[18] WANG Yushan, LIU Chengjian, CHEN Xiaoyan, CHEN Jixin, WU Shisen, YANG Wenchao, HUANG Daojian. Pollution Risk Assessments of Heavy Metals in Soils Around a Municipal Solid Waste Incinerator[J]. Journal of South China Normal University(Natural Science Edition),2020,52(05):57-64. 
[19]CHEN H, TENG Y, LUS, et al. Contamination features and health risk of soil heavy metals in China [ J]. Science of the Total Environment, 2015, 512: 143-153.

[20]SUN Bianbian, ZHAO Yinxin, CHANG Dan, WU Wenzhong, ZHANG Yong, TIAN Shuofeng. Distribution Characteristics and Ecological Risk Assessment of Soil Heavy Metals in Green Spaces of Yinchuan City[J].Research of Soil and Water Conservation,2020,27(06):262-268+277.

[21]Huang Shunsheng, Wu Xinmin, Yan Chaoyang, et al. Heavy Metal Concentrations and Their Spatial Distribution in Urban Soils of Nanjing[J].Urban Environment \& Urban Ecology,2007(02):1-4.

[22]Ma Tingjun, Lin Bingrong, Jia Changxi. Reclaimed Water Heavy Metal Residues Cluster Analysis and Principal Component Analysis[J]. Chinese Agricultural Science Bulletin,2010,26(24):318-321.

[23]Hakanson Lars. An $\times 10$ cological risk ind $\times 10 x$ for aquatic pollution control.a s $\times 10 d i m \times 10$ ntological approach. 1980, 14(8):975-1001. 


\section{Supplementary Files}

This is a list of supplementary files associated with this preprint. Click to download.

- GraphicalAbstract.jpg 